\title{
HopZ4 from Pseudomonas syringae, a Member of the HopZ Type III Effector Family from the YopJ Superfamily, Inhibits the Proteasome in Plants
}

\author{
Suayib Üstün, ${ }^{1,2}$ Patrick König, ${ }^{2}$ David S. Guttman, ${ }^{3,4}$ and Frederik Börnke ${ }^{1,2}$ \\ ${ }^{1}$ Leibniz-Institute for Vegetable and Ornamental Plants (IGZ), Theodor-Echtermeyer-Weg 1, 14979 Großbeeren, Germany; \\ ${ }^{2}$ Friedrich-Alexander-University Erlangen-Nuremberg, Staudtstr. 5, 91058 Erlangen, Germany; ${ }^{3}$ Department of Cell and \\ Systems Biology and ${ }^{4}$ Centre for the Analysis of Genome Evolution and Function, University of Toronto, Toronto, ON, Canada
}

Submitted 5 December 2013. Accepted 28 February 2014.

\begin{abstract}
The YopJ family of type III effector proteins (T3E) is one of the largest and most widely distributed families of effector proteins, whose members are highly diversified in virulence functions. In the present study, HopZ4, a member of the YopJ family of T3E from the cucumber pathogen Pseudomonas syringae pv. lachrymans is described. HopZ4 shares high sequence similarity with the Xanthomonas T3E XopJ, and a functional analysis suggests a conserved virulence function between these two T3E. As has previously been shown for XopJ, HopZ4 interacts with the proteasomal subunit RPT6 in yeast and in planta to inhibit proteasome activity during infection. The inhibitory effect on the proteasome is dependent on localization of HopZ4 to the plasma membrane as well as on an intact catalytic triad of the effector protein. Furthermore, HopZ4 is able to complement loss of XopJ in Xanthomonas spp., as it prevents precocious host cell death during a compatible Xanthomonas-pepper interaction. The data presented here suggest that different bacterial species employ inhibition of the proteasome as a virulence strategy by making use of conserved T3E from the YopJ family of bacterial effector proteins.
\end{abstract}

Many pathogenic bacteria are adapted to a narrow host range and evolved specific virulence strategies to overcome host defense. One of the main determinants of bacterial virulence and host range is the delivery of type three effector proteins (T3E) through their type three secretion system (T3SS) (Baltrus et al. 2011). These T3E promote pathogen multiplication and disease by interfering with host cellular pathways mainly associated with defense responses (Deslandes and Rivas 2012). However, many T3E in a given repertoire act in a cooperative and redundant manner, and thus, T3E repertoires are thought to specify host range and virulence strategies of a given pathogen (Baltrus et al. 2011; Cunnac et al. 2011). Although many effectors have a unique biochemical activity, they target conserved processes and cellular proteins in their respective host cells. This includes transcription, defense, and

Corresponding authors: S. Üstün; E-mail: uestuen@igzev.de and F. Börnke; E-mail: boernke@igzev.de

* The $\boldsymbol{e}$-Xtra logo stands for "electronic extra" and indicates that five supplementary figures and one supplementary table are published online.

(C) 2014 The American Phytopathological Society hormonal signaling, ubiquitination, and vesicle trafficking (Marino et al. 2012; Lee et al. 2013; Xin and He 2013). However, based on their homology or common structural and functional motifs, some T3E belong to larger protein families that could share conserved biochemical functions (Lee et al. 2012; Mukherjee et al. 2006; Tasset et al. 2010). One of the most common and widespread T3E families in plant and animal pathogenic bacteria is the YopJ superfamily of T3E originally classified as cysteine proteases (Hotson and Mudgett 2004; Lewis et al. 2011; Ma et al. 2006). A characteristic feature of this family is their catalytic triad consisting of the amino acids histidine, glutamic or aspartic acid, and cysteine. The foundation member of this effector family, YopJ from Yersinia pestis, has been shown to display acetyltransferase, de-sumoylating, and de-ubiquitinating activity (Mukherjee et al. 2006; Orth et al. 2000; Zhou et al. 2005). Homologues of YopJ have been identified in plant pathogenic bacteria including Pseudomonas (HopZ family), Ralstonia (PopP1 and PopP2), Erwinia (ORFB), and Xanthomonas (AvrRxv, AvrXv4, AvrBsT and XopJ) species as well as symbiotic bacteria, including Rhizobium sp. (NopJ) (Kimbrel et al. 2013; Lewis et al. 2011). Many of these effector proteins are able to suppress immune responses in their host organisms, dependent on their catalytic triad (Bartetzko et al. 2009; Lee et al. 2012; Mukherjee et al. 2006; Orth et al. 2000; Roden et al. 2004; Tasset et al. 2010; Zheng et al. 2011; Zhou et al. 2005). Recently, HopZ1a from the $P$. syringae pv. syringae A2 strain has been demonstrated to interact with an isoflavone biosynthesis enzyme GmHID1 (2-hyroxyisoflavone dehydratase) in soybean (Zhou et al. 2011). HopZ1a triggers the degradation of this enzyme by a yet-unknown mechanism and, hence, blocks the synthesis of the defense compound diazedin promoting bacterial growth of P. syringae (Zhou et al. 2011). The function of HopZ1a in Arabidopsis thaliana was recently uncovered by Lee and associates (2012), who could show an acetyltransferase activity of this effector. HopZ1a is able to autoacetylate and, also, transacetylate tubulin, causing disruption of microtubule networks. This, in turn, leads to the inhibition of the plant secretory pathway and suppresses cell wall-mediated defense (Lee et al. 2012).

Another well-characterized YopJ family member is XopJ from Xanthomonas campestris pv. vesicatoria. XopJ localizes to the plasma membrane (PM) of plant cells in a myristoylation-dependent manner and has been shown to block the secretory pathway dependent on its intact catalytic triad (Bartetzko et al. 2009; Thieme et al. 2007). Using a yeast twohybrid approach, the proteasomal subunit RPT6 was identified 
as an interaction partner of XopJ (Üstün et al. 2013). Both proteins associate at the PM of plant cells leading to the inhibition of the proteasome function by XopJ, an effect that is dependent on its localization and enzymatic activity. In the compatible interaction of $X$. campestris pv. vesicatoria with pepper plants, XopJ reduces the accumulation of salicylic acid (SA) to delay symptom development in a proteasome-dependent manner (Üstün et al. 2013). Thus, XopJ provides the first example of a T3E targeting the host cell proteasome.

Increasing evidence suggests that the ubiquitin-proteasome system (UPS) plays an important role in plant defense responses and cell-death execution (Marino et al. 2012). During the past few years, some components of the UPS, including E3 ligases, have been demonstrated to be part of the plant defense machinery. For example, members of the U-box E3 ligase family negatively regulate basal defense by ubiquitinating different defense-related proteins that are subsequently degraded via the 26S proteasome (Lu et al. 2011; Stegmann et al. 2012; Trujillo et al. 2008). Furthermore, the $26 \mathrm{~S}$ proteasome regulates celldeath induction during infection with $P$. syringae promoting the fusion of the vacuolar membrane with the PM (Hatsugai et al. 2009). Other subunits of the $26 \mathrm{~S}$ proteasome required for SA accumulation and innate immunity in plants against fungi and bacteria were identified (Yao et al. 2012).

On the other hand, the UPS is also exploited by various pathogens to enhance their virulence by translocating effector molecules that act as E3 ligases, e.g., AvrPtoB or, in the case of HopM1 from $P$. syringae, that use the $26 \mathrm{~S}$ proteasome to degrade target proteins (Göhre et al. 2008; Janjusevic et al. 2006; Nomura et al. 2006). Components of the 26S proteasome are also direct virulence targets of bacterial proteins. SylA, a secreted small nonribosomal peptide from $P$. syringae that is most likely taken up by the plant cell through oligopeptide transporters (Hofstetter et al. 2013), was shown to inhibit proteasome activity irreversibly (Groll et al. 2008). Recently, it was demonstrated that SylA targets the proteasome to suppress systemic acquired resistance (SAR), which is essential for the initial spread of $P$. syringae from wound infection sites (MisasVillamil et al. 2013). These findings imply that the $26 \mathrm{~S}$ proteasome is an eligible target for pathogens to subvert plant immunity and that it plays an important role in SA-mediated defense signaling.

The goal of the present study was to investigate whether pathogens that are adapted to different host plants use different or conserved effector proteins as means to target the $26 \mathrm{~S}$ proteasome and interfere with its function. Here, we could identify a previously uncharacterized effector member of the HopZ family from Pseudomonas syringae pv. lachrymans belonging to the YopJ super family. This T3E was named HopZ4, and it represents a close homologue of XopJ from $X$. campestris pv. vesicatoria. HopZ4 also interacts with RPT6 and leads to the suppression of proteasome activity, showing functional equivalence to XopJ. This implies that different bacterial species adapted to different hosts make use of highly similar T3E as virulence factors.

\section{RESULTS}

\section{HopZ4 from $P$. syringae pv. lachrymans is a member of the YopJ superfamily.}

In an in silico approach to find YopJ-like effector proteins that are highly similar in sequence to XopJ from $X$. campestris pv. vesicatoria, we identified a T3E from $P$. syringae pv. lachrymans M301315 (Pla107) showing 86\% amino acid identity to XopJ. P. syringae pv. lachrymans is the causal agent of angular leaf spot disease on cucumber plants and its genome sequence has previously been determined (Baltrus et al. 2011; Bhat et al. 2010). Owing to the fact that members of the YopJ family in Pseudomonas spp. are termed HopZ, the protein was named HopZ4. The same protein is also present in the genome in P. syringae pv. avellanae, showing $100 \%$ amino acid identity with HopZ4 (GenBank accession number EGK29639.1 [O'Brien et al. 2012]). We concentrated on HopZ4 from $P$. syringae pv. lachrymans for a detailed functional analysis. Sequence alignment with XopJ revealed that HopZ4 also contains the conserved catalytic triad (histidine [H133], glutamate [E152], cysteine [C194]) that is characteristic of all YopJ-like effector proteins (Fig. 1A). Both T3E, XopJ and HopZ4, possess a consensus myristoylation site (Gly2) that is present in a number of YopJ-like effectors from plant-pathogenic bacteria,
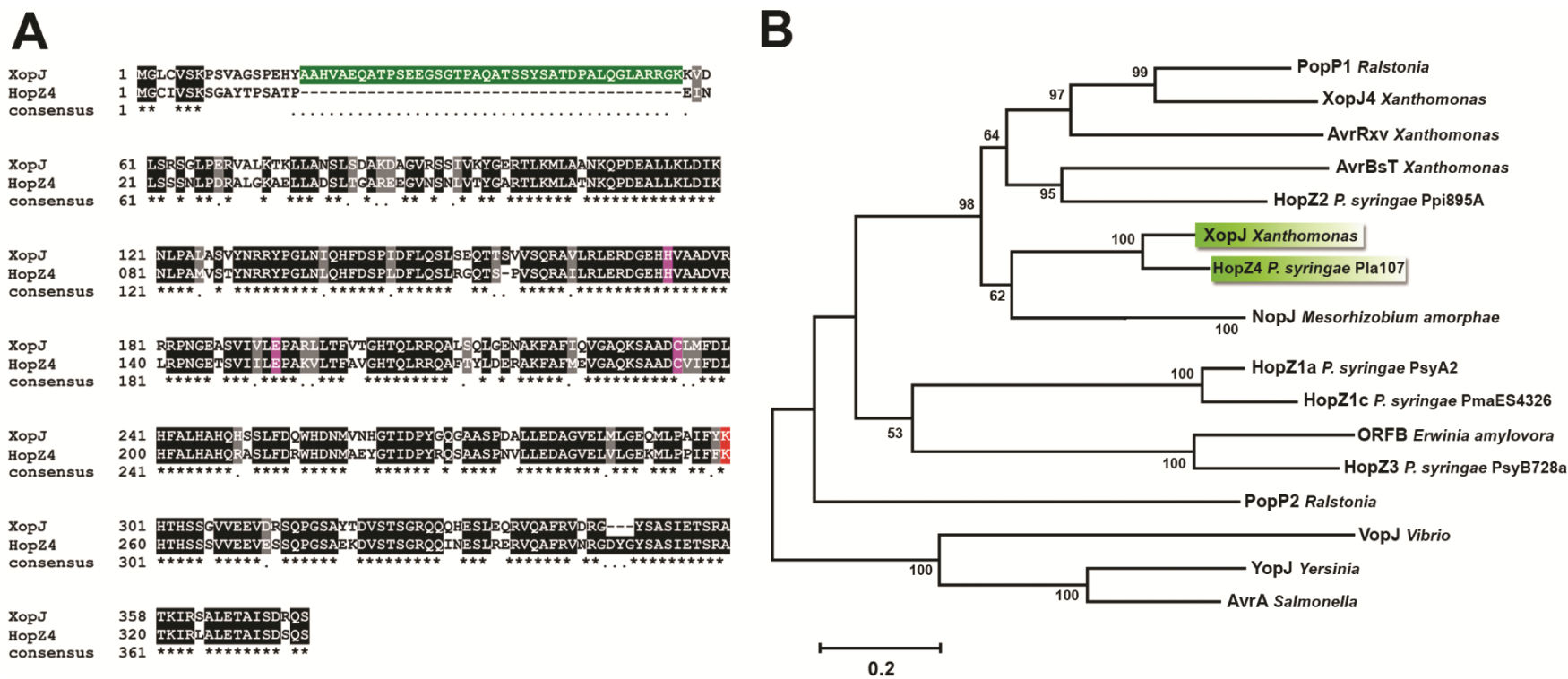

Fig. 1. HopZ4 is a member of the YopJ superfamily. A, Sequence alignment of HopZ4 and YopJ. The alignment was generated using CLUSTALW2 with default parameters and BoxShade 3.21. Positions of identical and similar sequences are boxed in black and gray, respectively. Amino acid sequence of HopZ4 was aligned with the sequence of XopJ. The catalytic triad is highlighted in pink and the conserved lysine residue in red. B, Phylogentic analysis of the YopJ superfamily. Neighbor-joining tree of YopJ family of type III effector proteins. Bootstrap support is indicated above each node, with only values $>50 \%$ being shown. 
in which it is required for localization to the PM (Bartetzko et al. 2009; Lewis et al. 2008; Thieme et al. 2007). Remarkably, HopZ4 lacks 40 amino acids at its amino-terminal part as compared with XopJ (Fig. 1A, highlighted in green). Taken together, the analysis of both sequences indicates that HopZ4 is highly similar in sequence to XopJ and, thus, might act in a XopJ-like manner.

A phylogenetic analysis of the complete YopJ family was conducted to examine the evolutionary relationship of HopZ4 to the other YopJ-like effector proteins. This comparative analysis revealed that HopZ4 clusters with XopJ and forms a distinct clade with a YopJ-like T3E from the symbiont Sinorhizobium fredii (NopJ) (Fig. 1B). These phylogenetic relationships demonstrate that HopZ4 is a member of the YopJ-like effector family present in Pseudomonas spp. and supports the idea that HopZ4 and XopJ may be functionally related homologs.

\section{Interaction of HopZ4 and RPT6 in yeast.}

Given the fact that HopZ4 and XopJ show high sequence identity and conservation of important amino acid motifs, we analyzed whether HopZ4 has the same eukaryotic target protein as XopJ. Previously, we demonstrated that XopJ interacts with the proteasomal subunit RPT6 in yeast and in planta to inhibit the proteasome function (Üstün et al. 2013). Thus, we used the yeast two-hybrid system to examine direct interactions between HopZ4 and RPT6 from different plant species. To this end, HopZ4 was used in fusion with the GAL4 binding domain and RPT6 was cloned into the yeast two-hybrid vector containing the activation domain. Direct interaction studies revealed that HopZ4 activates reporter gene expression and, thus, interacts with both RPT6 isoforms from Arabidopsis thaliana (isoforms a and b) as well as with RPT6 from Nicotiana tabacum and pepper, despite the sequence differences between HopZ4 and XopJ within the N-terminal part (Fig. 2). Deletion of the first 57 amino acids of XopJ did also not affect the interaction of RPT6 and XopJ, suggesting that the N-terminal part is not essential for binding to RPT6 (Supplementary Fig. S1). This result opens the possibility that HopZ4 may act in a XopJ-like manner and may target the proteasome to suppress plant defense.

\section{HopZ4 is localized to the plant PM.}

The presence of a consensus myristolyation motif at G2 in the amino acid sequence of HopZ4 suggests that HopZ4, similar to its close homolog XopJ, localizes to the plant PM. To address this question, we determined the subcellular localization of HopZ4 fused to the green fluorescent protein (GFP) upon transient expression in Nicotiana benthamiana leaves. Colocalization of HopZ4-GFP together with XopJ-mCherry would indicate that both proteins are localized to the plant PM, as XopJ was previously shown to be localized to that compartment (Bartetzko et al. 2009; Thieme et al. 2007). Thus, both fusion constructs were transiently coexpressed in $N$. benthamiana by agroinfiltration. The fluorescence signal was investigated $48 \mathrm{~h}$ after infiltration, using confocal laser scanning microscopy. We used XopJ-mCherry as a compartment-specific marker for the PM (Bartetzko et al. 2009). The overlapping fluorescence pattern at the PM of HopZ4-GFP and XopJ-mCherry (Fig. 3A) suggests that both proteins colocalize to the PM. A mutation within the catalytic triad (C194A) does not affect proper PM localization of HopZ4 (Fig. 3B), which was also reported for the catalytic mutant of XopJ (Bartetzko et al. 2009). However, a G2A exchange resulted in a shift of the localization of HopZ4-GFP to the cytosol and cytosolic strands (Fig. 3C), indicating the requirement of the myristolyation motif for PM targeting. Accumulation and stability of the transiently expressed fusion proteins was verified by immunoblot analysis $48 \mathrm{~h}$ postinfection (hpi) (Supplementary Fig. 2). In addition, the sequence comparison between XopJ and HopZ4 revealed that HopZ4 possesses a cysteine at position 3 that could serve as a target for palmitoylation, a modification also mediating membrane association, often in concert with myristolyation (Batistic et al. 2008). Using mutational analysis to assess the role of this residue in PM localization of HopZ4, we could show that HopZ4 (C3A)-GFP was no longer able to localize to the PM, indicating the importance of this residue for PM targeting (Supplementary Fig. 3). Simultaneous mutation of the putative myristolyation and palmitoylation motifs leads to a loss of membrane localization of HopZ4, as the double mutant HopZ4 (G2AC3A) is localized to the cytosol and nucleus. In summary, these results support the notion that HopZ4 is directed to the plant PM by an N-myristoylation signal, possibly involving an additional palmitoylation at C3.

\section{Interaction of HopZ4 and RPT6 in planta.}

To confirm whether HopZ4 and RPT6 are able to interact in planta, bimolecular fluorescence complementation (BiFC) was performed in $N$. benthamiana, using transient expression via

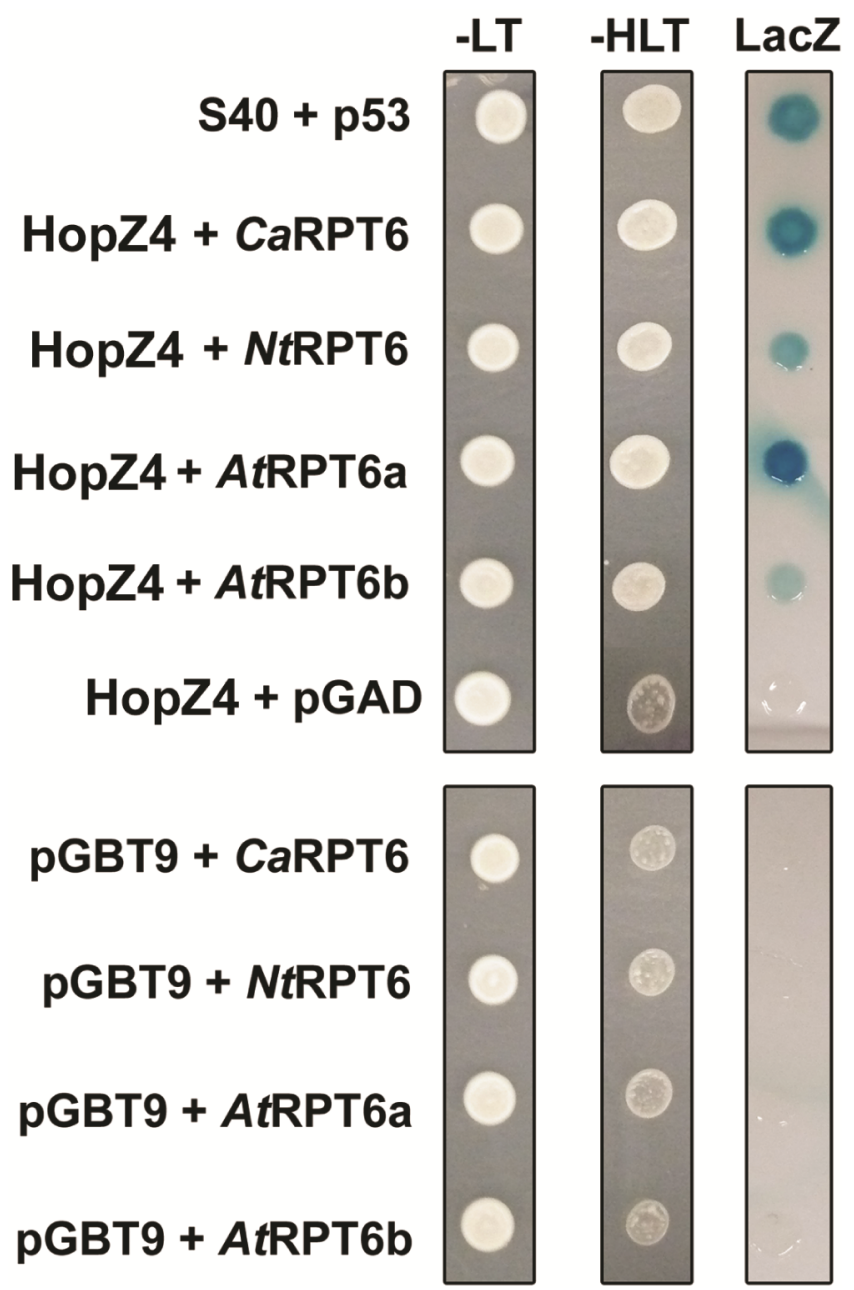

Fig. 2. Interaction of HopZ4 with RPT6 in yeast two-hybrid assays HopZ4 fused to the GAL4 DNA-binding domain was expressed in combination with RPT6 fused to the GAL4 activation domain (AD) in yeast strain Y190. Cells were grown on selective media before a LacZ filter assay was performed. pSV40/p53 served as positive control, while the empty AD vector served as negative control. NtRPT6 = Nicotiana tabacum RPT6, AtRPT6a = Arabidopsis thaliana $\mathrm{RPT} 6$ isoform a, AtRPT6b $=A$. thaliana RPT6 isoform b, CaRPT6 = Capsicum annuum RPT6. $-\mathrm{LT}=$ yeast growth on medium without Leu and Trp, - HLT $=$ yeast growth on medium lacking His, Leu, and Trp, indicating expression of the HIS3 reporter gene. LacZ, activity of the $l a c Z$ reporter gene. 
agroinfiltration. To this end, HopZ4 and RPT6 were fused to the N-terminal part of the yellow fluorescent protein derivate Venus $\left(\right.$ Venus $^{\mathrm{N}}$ ) and the C-terminal part of Venus $\left(\right.$ Venus ${ }^{\mathrm{C}}$ ), respectively. Reconstitution of the fluorescence signal after transient coexpression by agroinfiltration in $N$. benthamiana indicated that HopZ4 interacts with RPT6 in planta (Fig. 4A). Consistent with the PM localization of HopZ4, the fluorescence appeared to be at the PM, as no cytosolic strands were visible. The interaction of XopJ and RPT6, as well as the homodimerization of the cytosolic fructose-1,6-bisphosphatase (FBPase), served as a positive control (Fig. 4D and E). Agroinfiltration of HopZ4-Venus ${ }^{N}$ together with FBPase-Venus ${ }^{C}$ or FBPase-Venus ${ }^{\mathrm{N}}$ together with RPT6-Venus ${ }^{\mathrm{C}}$ served as negative controls and did not result in fluorescence (Fig. 4F and G).

To further corroborate this finding, coimmunoprecipitation was used to determine whether HopZ4 is able to bind to RPT6 in planta. To this end, RPT6-GFP was transiently coexpressed together with HopZ4-HA (hemagglutinin) or XopJ-HA in $N$. benthamiana. Two days after agroinfiltration, RPT6-GFP was pulled down using GFP-trap beads, and the eluates were analyzed by immunoblot with anti-GFP and anti-HA antibodies. RPT6-GFP was able to pull down HopZ4-HA, similar to XopJHA, verifying the interaction of both proteins in planta (Fig. $4 \mathrm{H})$. Transient expression of XopJ-HA reproducibly produced two bands in Western blots (Fig. 4H), both of which can be pulled down by RPT6-GFP. This might point towards a posttranslational modification of this effector protein in planta.

As previous coimmunoprecipitation studies suggested that the biological activity and myristoylation of XopJ were not required for its interaction with RPT6 (Üstün et al. 2013), we investigated whether these features were also dispensable for the interaction of HopZ4 and RPT6. Thus, the catalytic mutant HopZ4(C194A) as well as the HopZ4(G2A) variant were tested in a BiFC assay for interaction with RPT6. Both forms of HopZ4 were still able to interact in planta with RPT6 (Fig. 4B and C). While the catalytic mutant of HopZ4 associated with RPT6 at the PM, being in accordance with the PM localization of HopZ4(C194A), the G2A mutant of HopZ4 interacted in the cytoplasm (Fig. $4 \mathrm{~B}$ and C). This indicates that the catalytic activity and myristoylation of HopZ4 is not essential for association with RPT6 in planta.

\section{HopZ4 inhibits proteasome activity.}

After having established that the Pseudomonas T3E HopZ4 also interacts with the proteasomal subunit RPT6 in planta and in yeast, we next investigated whether HopZ4 acts in a XopJlike manner resulting in the inhibition of the proteasome activity. Chymotrypsin-like activity of the proteasome in the presence of HopZ4 was measured using a fluorogenic substrate (Suc-LLVYAMC) (Üstün et al. 2013). Similar reductions of proteasome activity were found $48 \mathrm{~h}$ after transient expression of HopZ4myc and XopJ-myc in $N$. benthamiana (Fig. 5A). Both effector proteins led to an approximately $40 \%$ inhibition of proteasome activity compared with leaves infiltrated with the empty vector control (Fig. 5A). Immunoblot analysis confirmed the proper expression of XopJ-myc and HopZ4-myc 48 hpi (Fig. 5B).

The suppression of the proteasome activity by XopJ is dependent on the catalytic triad and myristoylation. Therefore,

\section{GFP}
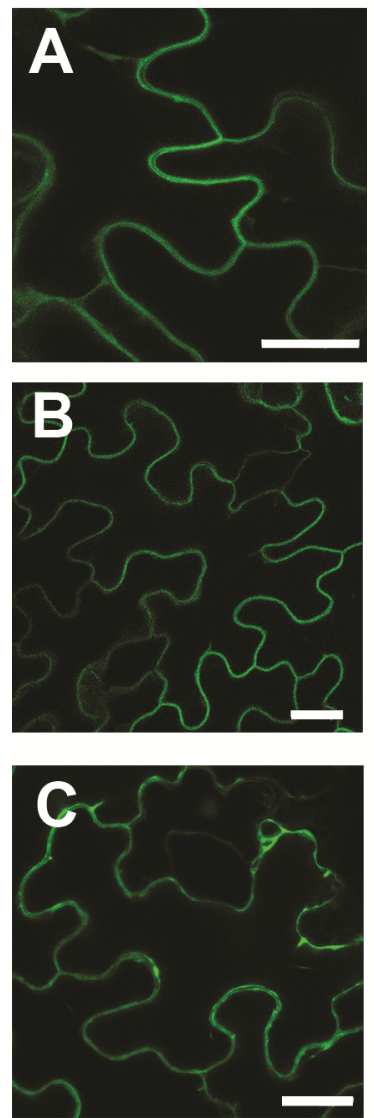

mCherry
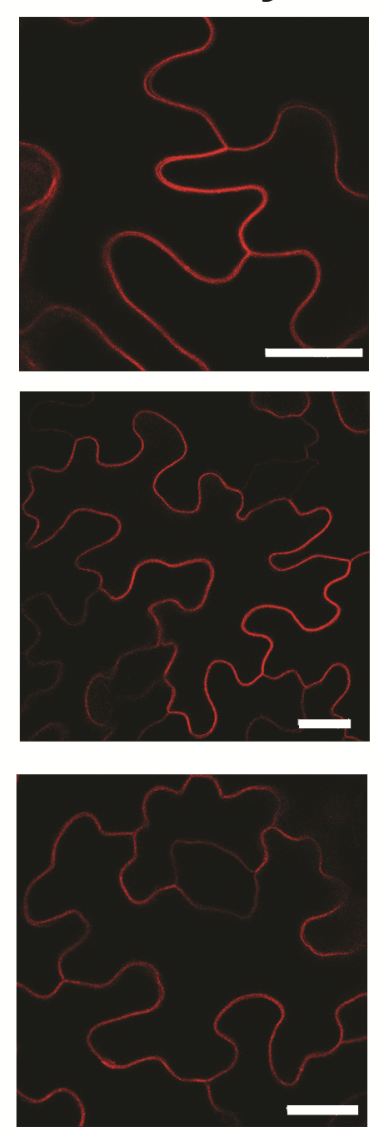

chlorophyll
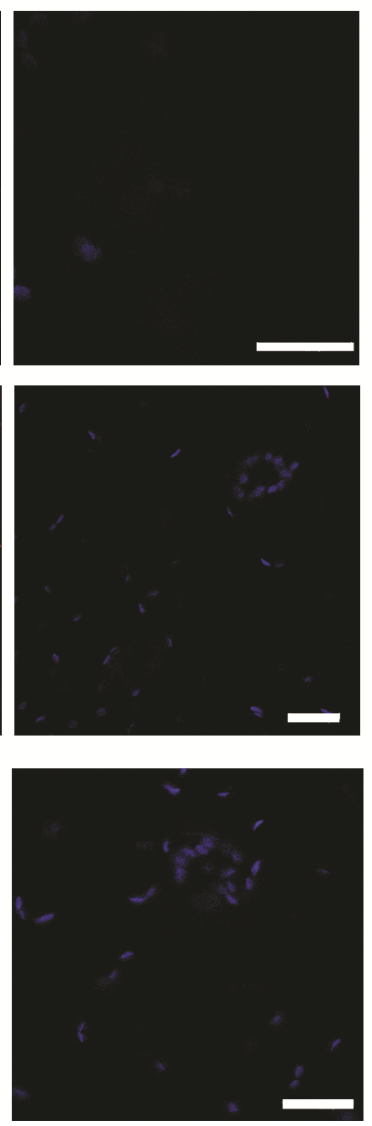

merge
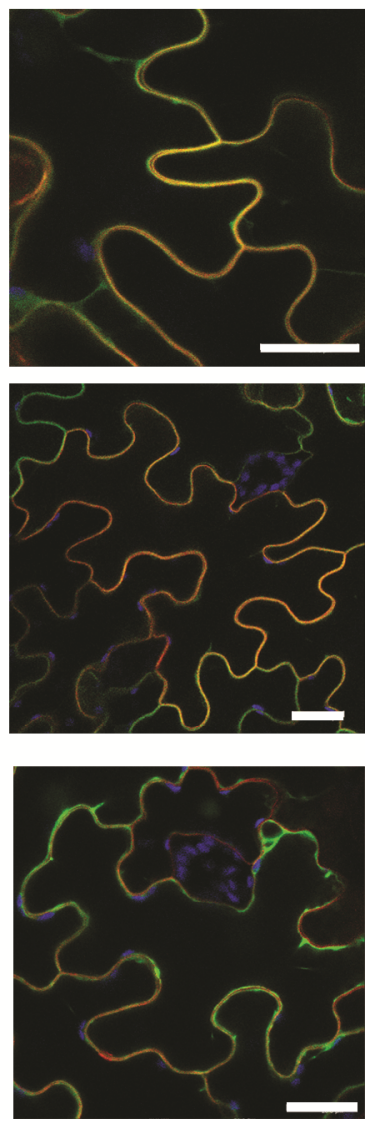

Fig. 3. Subcellular localization of HopZ4 and its variants. A, Subcellular localization of HopZ4-GFP, B, HopZ4(C194A)-GFP, and C, HopZ4(G2A)-GFP, together with XopJ-mCherry fusion in Nicotiana benthamiana leaves transiently transformed by agroinfiltration. The green fluorescence (GFP), red fluorescence (mCherry), and chlorophyll autofluorescence $(\mathrm{Chl})$ were monitored separately to prevent cross-talk of the fluorescence channels, and the resulting fluorescence images were merged. Bars $=20 \mu \mathrm{m}$. Pictures show a representative result of at least three repetitions. 
we tested the catalytic mutant and myristoylation mutant of HopZ4 for the ability to affect the proteasome function. Transient expression of both variants together with the wild-type HopZ4 protein in $N$. benthamiana revealed that HopZ4 also requires its catalytic activity and proper localization to inhibit the proteasome activity in plants, as both HopZ4 mutants lost the ability to reduce the activity of the proteasome (Fig. 5C). Expression of all proteins was confirmed by immunoblot analysis with an anti-myc antibody 48 hpi (Fig. 5D). In addition, the HopZ4(C3A) variant was also not able to suppress proteasome activity (Supplementary Fig. 4), further supporting the idea that PM localization is required for HopZ4 function.

\section{HopZ4 interferes with protein secretion.}

Protein transport to the plant PM and secretion into the apoplast play an essential role during plant immunity and has been shown to be target of several T3E proteins (Bartetzko et al. 2009; Nomura et al. 2006; Schulze et al. 2012). One of these effectors is XopJ, which has previously been shown to inhibit secretion of a secreted (sec)GFP reporter (Bartetzko et al. 2009). Moreover, the inhibition of the proteasome by the proteasome inhibitor MG132 also affected protein secretion and explained how XopJ possibly interferes with the secretory pathway (Üstün et al. 2013). As HopZ4 is also capable of reducing the proteasome activity, we analyzed whether HopZ4 is able to inhibit protein secretion in a similar way. To this end, $N$. benthamiana leaves transiently coexpressing secGFP, a GFP variant that is secreted into the apoplast (Batoko et al. 2000), and HopZ4 were examined using confocal microscopy. Coexpression of XopJ together with secGFP served as a positive control. Only weak fluorescence was detected if secGFP was expressed alone (Fig. 6A). By contrast, coexpression of HopZ4 and secGFP led to an increase in secGFP fluorescence in an endoplasmic reticulum (ER)-like pattern, comparable to the fluorescence pattern obtained after coexpression of secGFP with XopJ (Fig. 6C and D compared with B). This indicates that HopZ4 impaired GFP secretion into the apoplast. In addition, the inhibition of protein secretion depends on a functional catalytic triad, given that HopZ4(C194A) transiently coexpressed with secGFP did not affect secGFP trafficking to the apoplast (6E and F). Protein levels of HopZ4 and its catalytic inactive variant together with secGFP expression were confirmed via immunoblot analysis with an anti-myc antibody (Supplementary Fig. 5).

Fig. 4. HopZ4 interacts with RPT6 in planta. A to G, Visualization of protein interactions in planta by the bimolecular fluorescence complementation assay. A, Yellow fluorescent protein (YFP) confocal microscopy images show Nicotiana benthamiana leaf epidermal cells transiently expressing HopZ4-Venus ${ }^{\mathrm{N}}$ in combination with RPT6-Venus ${ }^{\mathrm{C}}$. A close-up of the same cells (right panel) at $2.5 \times$ higher magnification shows that the YFP fluorescence aligns with the plasma membrane. B, Fluorescence image of HopZ4(C194A)-Venus ${ }^{\mathrm{N}}$ - and RPT6-Venus ${ }^{\mathrm{C}}$-expressing cells. C, Combination of HopZ4(C2A)-Venus ${ }^{\mathrm{N}}$ and RPT6-Venus ${ }^{\mathrm{C}}$. D, The combination of XopJ-Venus ${ }^{\mathrm{C}}$ and RPT6-Venus ${ }^{\mathrm{N}}$ serves as a positive control. E, A positive control showing the dimerization of fructose-1,6-bisphosphatase (FBPase) within the cytosol. F, The combination of HopZ4-Venus ${ }^{\mathrm{C}}$ with FBPase-Venus $^{\mathrm{N}}$ does not induce YFP fluorescence. F, RPT6-Venus ${ }^{\mathrm{C}}$ and FBPase-Venus $^{N}$ negative control. Bars $=20 \mu \mathrm{m}$. The experiment has been repeated three times with similar results. H, Coimmunoprecipitation of RPT6-GFP (green fluorescent protein) with HopZ4-HA (hemagglutinin) and XopJ-HA. NtRP6-GFP was transiently coexpressed in leaves of $N$. benthamiana using agroinfiltration with either HopZ4-HA or XopJ-HA. After $48 \mathrm{~h}$, total proteins (Input) were subjected to immunoprecipitation (Eluate) with GFP-Trap beads, followed by immunoblot analysis using either anti-GFP or anti-HA antibodies. Expression of HopZ4HA served as a negative control. At least three repetitions with similar results have been conducted.
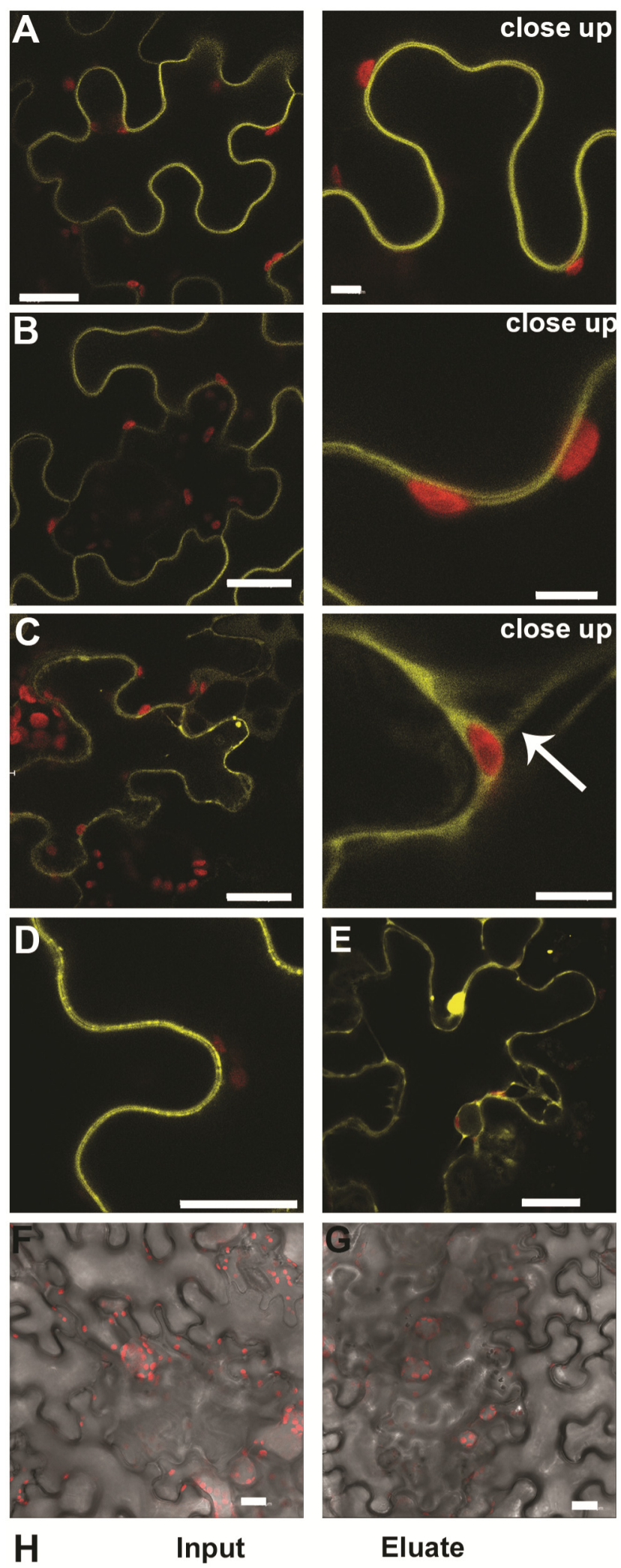

Eluate
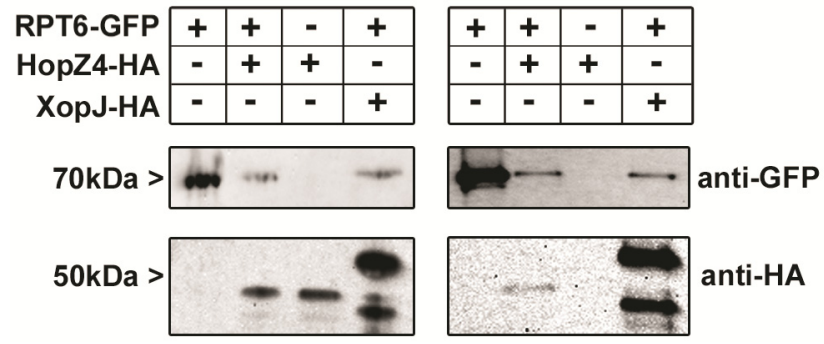
HopZ4 complements the loss of XopJ

during compatible interaction

of $X$. campestris pv. vesicatoria with pepper plants.

XopJ has been shown to inhibit the proteasome function to prevent host cell-death responses in the compatible $X$. campestris pv. vesicatoria-pepper interaction (Üstün et al. 2013). In order to determine whether XopJ homolog HopZ4 is a functional equivalent to the previously characterized XopJ, we sought to analyze whether HopZ4 is able to complement the $X$. campestris pv. vesicatoria $\triangle$ xopJ mutant strain. Thus, the broad-host vector pBBR1 MCS-5, containing the HopZ4 open reading frame (ORF) tagged with $\mathrm{HA}$ to facilitate immunological detection under control of the lac promoter, was introduced into the $X$. campestris pv. vesicatoria $\Delta x o p J$ strain (X. campestris pv. vesicatoria AxopJ [HopZ4-HA]). Phenotype development and symptom production after infection of susceptible pepper plants (Capsicum annuum cv. Early Cal Wonder) with a high bacterial titer $\left(10^{8} \mathrm{CFU} / \mathrm{ml}\right)$ of the $X$. campestris pv. vesicatoria wild-type and $\Delta x o p J$ strains in comparison with
$X$. campestris pv. vesicatoria $4 x o p J$ (HopZ4-HA) was assessed. Leaves infected with the $X$. campestris pv. vesicatoria strain lacking XopJ displayed earlier host cell-death symptoms in comparison with those infected with $X$. campestris pv. vesicatoria wild-type at 3 days postinfection (dpi), as reported previously (Üstün et al. 2013). The introduction of HopZ4 into the $X$. campestris pv. vesicatoria $\triangle x o p J$ strain abolished necrosis induction, suggesting that HopZ4 is sufficient to inhibit host cell-death induction in pepper leaves (Fig. 7A). Proper expression of HopZ4 was verified by immunoblot analysis directed against the HA tag (Fig. 7B). To investigate the delay of host cell death by HopZ4 in more detail, cell death was observed by trypan blue staining, which specifically stains dead cells. Consistent with the macroscopic phenotypes, almost all cells were stained with trypan blue in tissue infected with the $X$. campestris pv. vesicatoria $\triangle x o p J$ strain, whereas in leaves infected with X. campestris pv. vesicatoria or $\Delta x o p J$ (HopZ4-HA), only a few cells were stained (Fig. 7C). The observed phenotypes are summarized in Figure 7D. From these data, it becomes

A

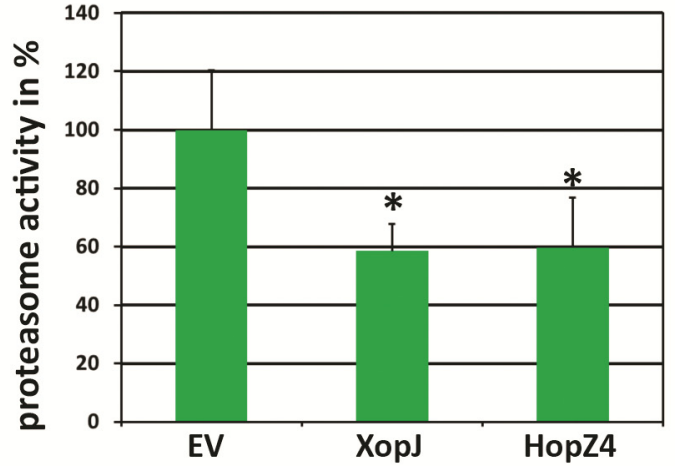

B

EV XopJ HopZ4

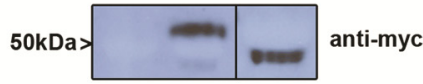

C

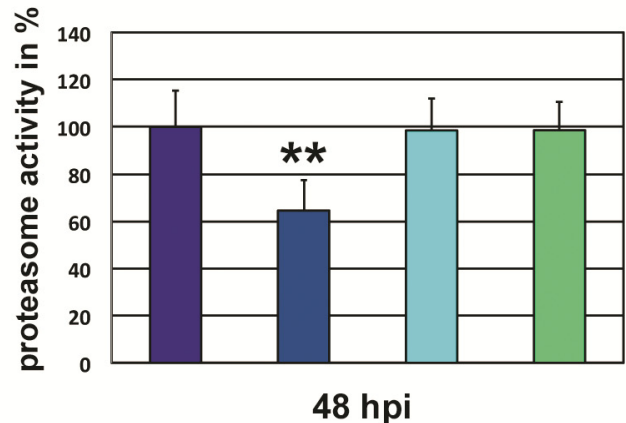

EV

HopZ4

HopZ4(C194A)

HopZ4(G2A)
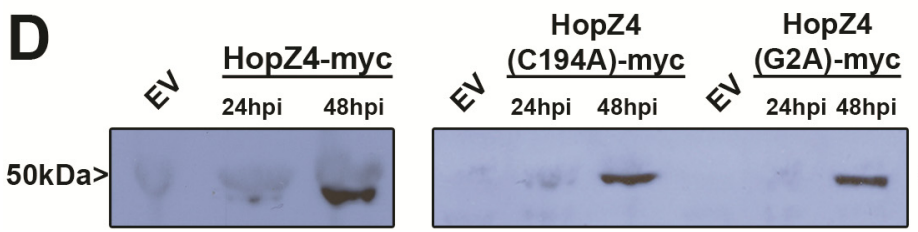

anti-myc

Fig. 5. Transient expression of HopZ4 in Nicotiana benthamiana suppresses proteasome activity. A, Proteasome activity in N. benthamiana leaves transiently expressing XopJ-myc or HopZ4-myc proteins. HopZ4 and XopJ along with an empty vector (EV) control were transiently expressed in leaves of $N$. benthamiana using agroinfiltration. After $48 \mathrm{~h}$, relative proteasome activity in total protein extracts was determined by monitoring the breakdown of the fluorogenic peptide suc-LLVY-AMC at $30^{\circ} \mathrm{C}$ in a fluorescence spectrophotometer. The empty vector control was set to $100 \%$. Data represent the mean standard deviation (SD) $(n=3)$. The experiment has been repeated more than three times with similar results. B, Immunodetection of proteins indicated using an antimyc antibody and amido black staining of the membrane to control for equal protein loading. C, Proteasome activity in $N$. benthamiana leaves transiently expressing HopZ4-myc and its variants along with an empty vector (EV). After $48 \mathrm{~h}$, relative proteasome activity in total protein extracts was determined by monitoring the breakdown of the fluorogenic peptide suc-LLVY-AMC at $30^{\circ} \mathrm{C}$ in a fluorescence spectrophotometer. The empty vector control was set to $100 \%$. Data represent the mean SD $(n=3)$. The experiment has been repeated more than three times with similar results. D, Protein levels of HopZ4-myc, HopZ(G2A)-myc and HopZ4(C194A)-myc were analyzed by immunoblot using an anti-myc antibody $48 \mathrm{~h}$ postinfection. Amido black staining shows equal protein loading. 
apparent that the $X$. campestris pv. vesicatoria $\triangle x o p J$ (HopZ4HA) strain behaves like the $X$. campestris pv. vesicatoria wildtype strain, as only $20 \%$ of five individual pepper plants exhibit chlorosis and $80 \%$ of the plants showed beginning symptom development. In contrast, a loss of XopJ resulted in necrosis induction in $80 \%$ of infected pepper plants (Fig. 7D). In order to quantify the ability of HopZ4 to complement the loss of XopJ in X. campestris pv. vesicatoria, we measured ionleakage from infected tissue as a proxy for cell integrity. In accordance with the observed leaf necrosis, infection with the $X$. campestris pv. vesicatoria $\Delta x o p J$ strain leads to significantly enhanced ion leakage $3 \mathrm{dpi}$ as compared with $X$. cam- pestris pv. vesicatoria wild type-infected leaves (Fig. 7E). Episomal expression of HopZ4 in the $X$. campestris pv. vesicatoria $\triangle x o p J$ background reduced conductivity to $X$. campestris pv. vesicatoria wild-type levels. Collectively, these data demonstrate that HopZ4 complements the loss of XopJ during a compatible interaction of $X$. campestris pv. vesicatoria with pepper plants.

\section{DISCUSSION}

Members of the YopJ-like T3E family are widely distributed among plant and animal pathogenic bacteria as well as symbi-
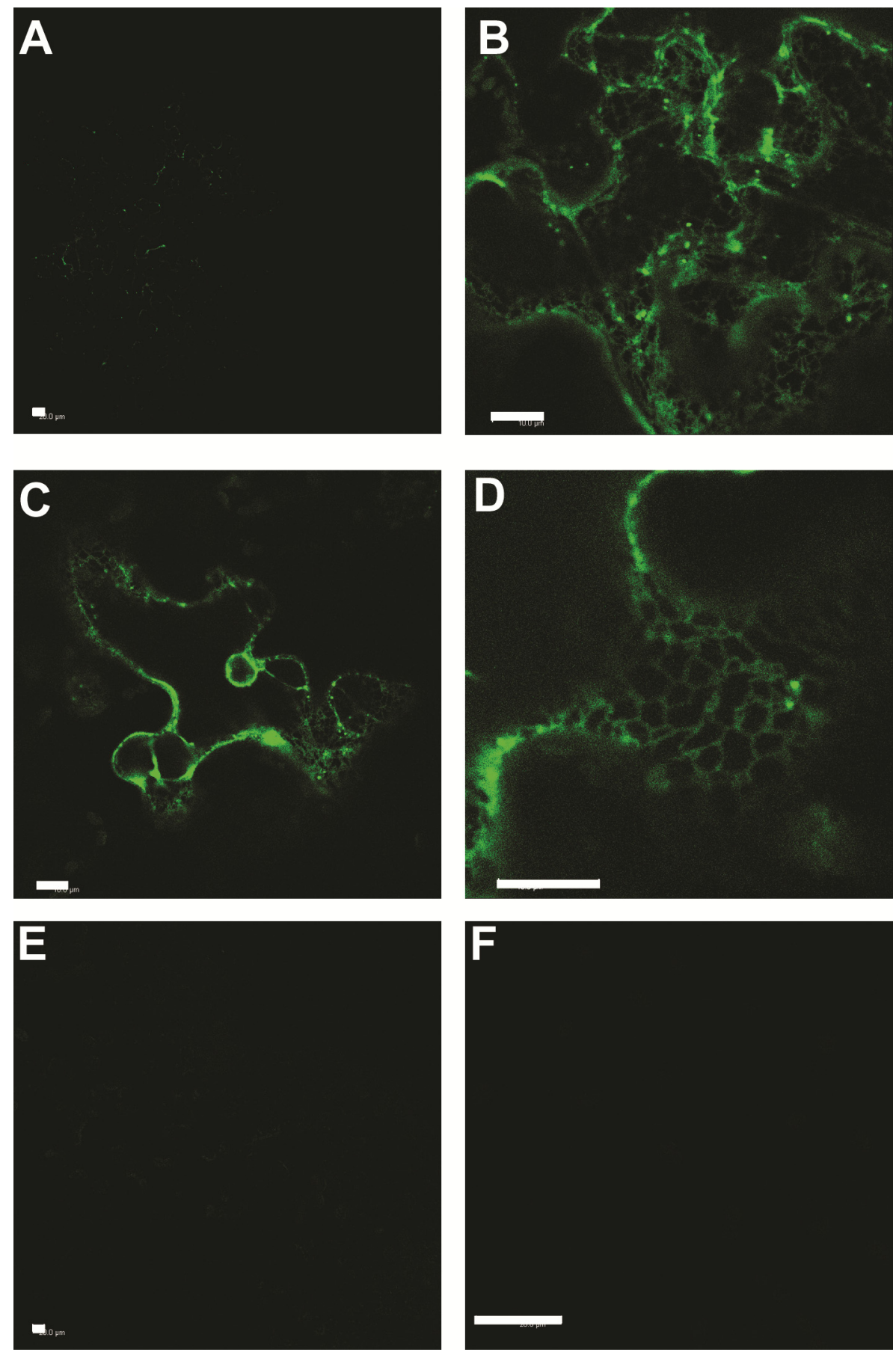

Fig. 6. HopZ4 blocks protein secretion and leads to the accumulation of secGFP (secreted green fluorescent protein) within a cytosolic reticulum. A, Confocal images of Nicotiana benthamiana leaf epidermis cells transiently expressing secGFP alone and $\mathbf{B}$, together with XopJ. C, Coexpression of secGFP with HopZ4 results in a build-up of GFP fluorescence within the cell. D, Coexpression of secGFP with HopZ4 at higher magnification. E, Coexpression of secGFP together with the HopZ4(C194A) variant disrupted in the catalytic triad. F, Close-up of a secGFP/HopZ4(C194A) coexpressing leaf cell. Bars $=20 \mu \mathrm{m}$. 
onts (Ma et al. 2006). Based on their relatedness and conservation of essential amino acid residues, it has been questioned whether YopJ-like effectors can target conserved structures and utilize similar mechanisms to manipulate host cellular processes. However, the few examples for which a specific host cellular target has been identified suggest a high degree of functional specification among family members (Lewis et al. 2011). Recently, we have shown that the $X$. campestris pv. vesicatoria T3E XopJ targets the proteasomal subunit RPT6 to inhibit proteasome activity, thereby suppressing SA-dependent defense signaling and precocious host cell death (Üstün et al. 2013). Thus, the present study was aimed to determine whether other members of the YopJ-like effector family would be able to target the proteasome.
Here, we functionally characterized HopZ4, a YopJ-like effector protein from the cucumber pathogen $P$. syringae pv. lachrymans (Pla107). Analogous to the $X$. campestris pv. vesicatoria effector XopJ, HopZ4 targets RPT6 at the PM to inhibit proteasome activity dependent on its catalytic triad and localization. Moreover, HopZ4 complements the loss of XopJ in a compatible interaction of $X$. campestris pv. vesicatoria with pepper, supporting the idea that HopZ4 displays XopJlike activity. Our results suggest that different bacterial species make use of the same YopJ-family effector proteins to evolve specific virulence strategies for pathoadaptation, a process that could be mediated by horizontal gene transfer.

Despite the sequence diversity within this effector family and the observed host specificity of the respective bacteria,
A
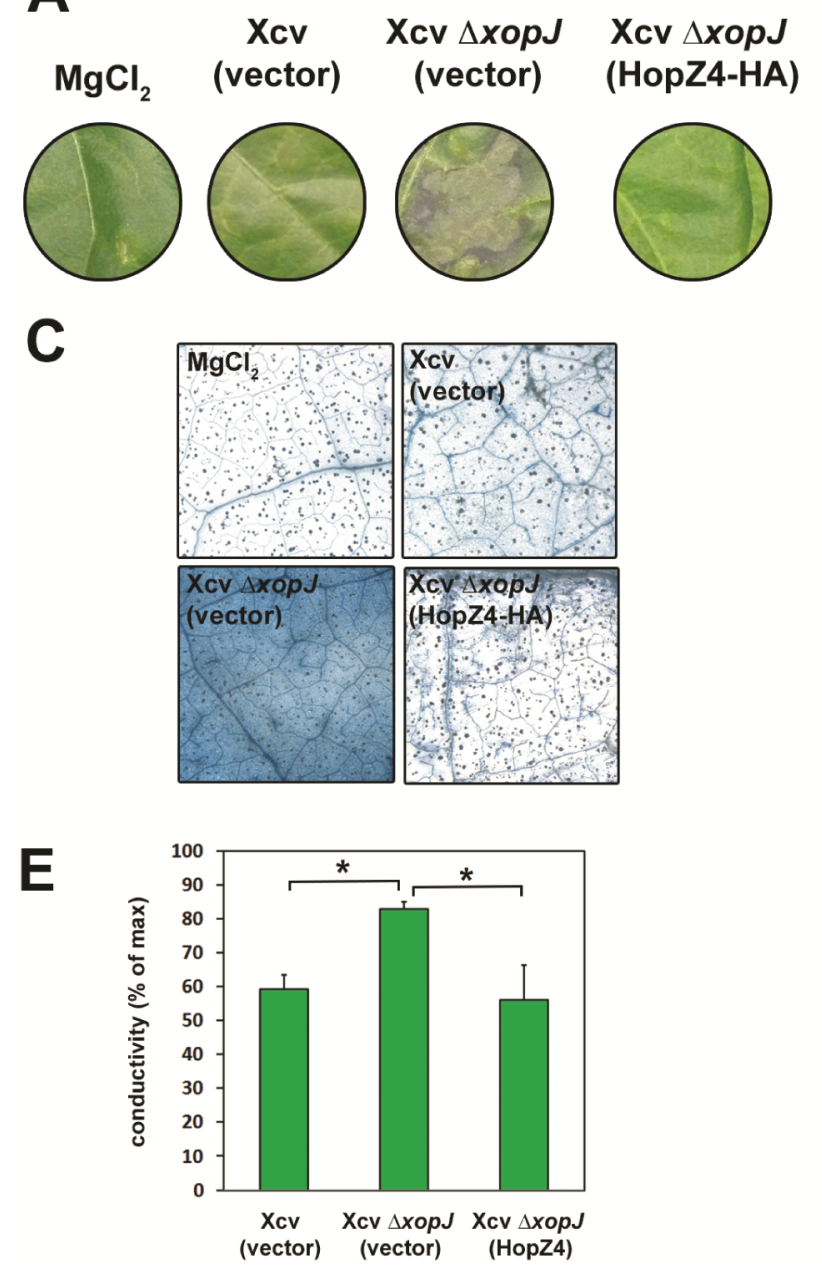

B
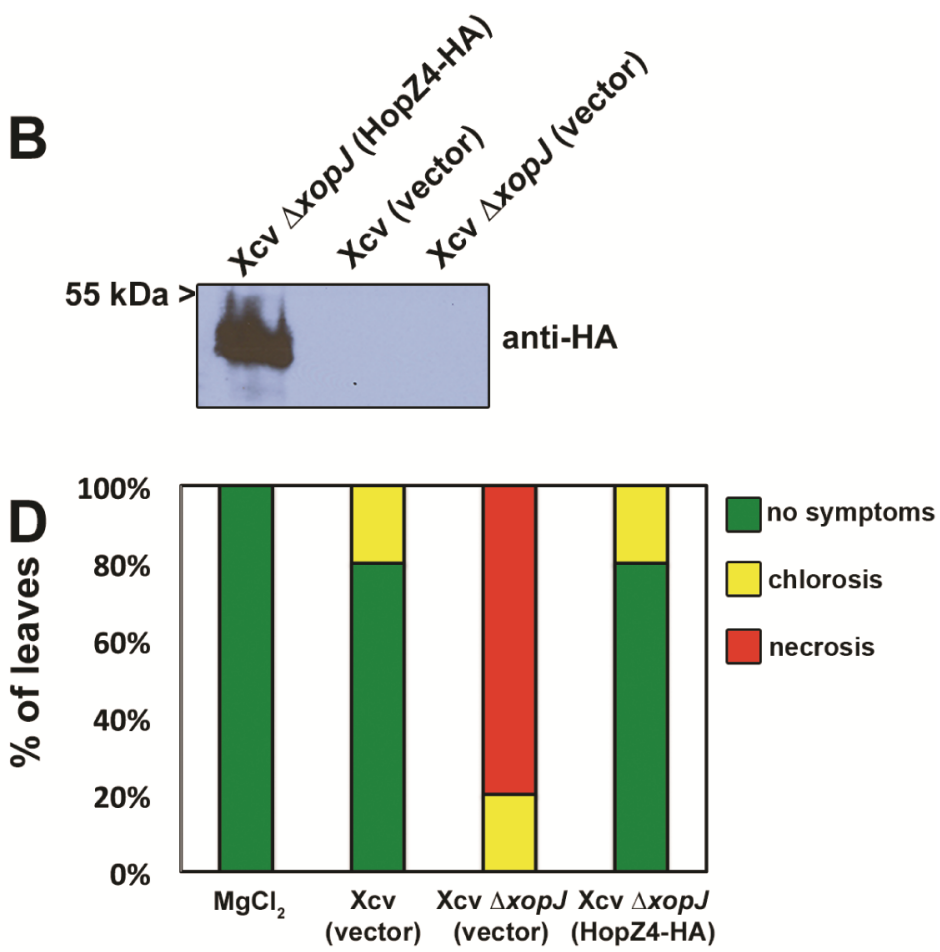

Fig. 7. HopZ4 complements the loss of XopJ when delivered by Xanthomonas campestris pv. vesicatoria $4 x o p J$. A, X. campestris pv. vesicatoria (vector), X. campestris pv. vesicatoria $\Delta x o p J$ (vector), $X$. campestris pv. vesicatoria $\Delta x o p J$ (HopZ4-HA) together with the infiltration control $\mathrm{MgCl}_{2}$ were infiltrated at a bacterial density of $1 \times 10^{8} \mathrm{CFU} \mathrm{ml}^{-1}$ into leaves of pepper Capsicum annuum cv. Early Cal Wonder (ECW) plants. The leaf phenotype was photographed at 3 days postinfection (dpi). B, Protein extracts from pepper leaves infiltrated with $1 \mathrm{mM} \mathrm{MgCl}_{2}$, X. campestris pv. vesicatoria (vector), X. campestris pv. vesicatoria $\triangle x o p J$ (vector), X. campestris pv. vesicatoria $4 x o p J$ (HopZ4-HA) at 3 dpi were prepared. Equal volumes representing approximately equal protein amounts of each extract were immunoblotted, and proteins were detected using antihemagglutinin (HA) antiserum. C, Trypan blue staining of infected tissue of ECW plants reveals reduced cell death in the presence of functional HopZ4. X. campestris pv. vesicatoria (vector), X. campestris pv. vesicatoria $\Delta x o p J$ (vector), and $X$. campestris pv. vesicatoria $\triangle$ xopJ (HopZ4-HA) were inoculated at a bacterial density of $1 \times 10^{8} \mathrm{CFU}^{-1}$ into leaves of pepper ECW plants. Samples of infected and untreated leaves were taken 3 dpi and were stained with trypan blue. Dead plant cells stain blue. Gray and black spots represent calcium oxalate crystals. D, Summary of observed phenotypes. Five pepper plants were infected with the different X. campestris pv. vesicatoria strains indicated and were then scored for phenotype development at 3 dpi. E, Delivery of HopZ4 by X. campestris pv. vesicatoria leads to reduced ion leakage in pepper. Ion leakage was measured in pepper plants infected with X. campestris pv. vesicatoria (vector), X. campestris pv. vesicatoria AxopJ (vector), and $X$. campestris pv. vesicatoria $\triangle$ xopJ (HopZ4-HA). Conductivity was measured at the time points indicated. Data represent the mean standard deviation $(n=3)$. Significant differences are indicated by asterisks (* indicates $P<0.05$ ) and were calculated using Student's $t$-test. 
studies on YopJ homologues imply that these effectors share a significant similarity in molecular function. YopJ from Yersinia pestis was shown to possess acetyltransferase activity in animals, blocking the phosphorylation of mitogen-activated protein kinases through acetylation (Mukherjee et al. 2006; Orth 2002). Another effector from an animal pathogen displaying acetyltransferase activity is AvrA from Salmonella enterica, a close homologue of YopJ (Mittal et al. 2010). However, despite their similar biochemical activity, both effector proteins possibly do target different cellular proteins (Du and Galan 2009). In spite of close amino acid sequence similarity and conserved biochemical activity among effector proteins from the YopJ superfamily, there is no pair of YopJ-family effector homologues so far identified that share the same target protein.

One of the best-described effector families of the YopJ superfamily that has undergone allelic diversification to develop different virulence mechanisms is the HopZ family from $\mathrm{Pseu}$ domonas syringae, including HopZ1, HopZ2, and HopZ3 (Ma et al. 2006). HopZ1 has three functional allelic forms (HopZ1a, $\mathrm{b}$, and c), whose diversification is likely driven by selective pressure exerted by the host immune system (Ma et al. 2006). Although all three allelic forms display high sequence similarity, recognition of these effector molecules by the plant's immune system seems to vary heavily (Lewis et al. 2008; Ma et al. 2006; Zhou et al. 2009). The two other members of the HopZ family are quite divergent from the ancestral HopZ1, with HopZ2 being closely related to AvrBsT from $X$. campestris pv. vesicatoria and HopZ3 sharing high identity to the effector ORFB from Erwinia amylovora (Ma et al. 2006). HopZ2 and HopZ3 are thought to be acquired by horizontal gene transfer in response to positive selection imposed by the host immune system (Ma et al. 2006). Previous studies showed that the ancestral HopZ1a targets the tubulin network in Arabidopsis thaliana by acetylating itself and tubulin (Lee et al. 2012). However, HopZ1a seems to have various targets in different plant species, as HopZ1a targets GmHID1 (2-hydroxyisoflavone dehydratase), an enzyme involved in the biosynthesis of isoflavones in soybean, and degrades this protein via an unknown mechanism (Zhou et al. 2011). In a recent report, Jiang and associates (2013) could demonstrate that HopZ1a interacts with jasmonate ZIM-domain (JAZ) proteins from soybean and Arabidopsis that are key transcriptional repressors of the jasmonate (JA) signaling pathway. HopZ1a is able to acetylate and degrade JAZ proteins activating JA signaling during infection and partially mimicking the function of the bacterial phytotoxin coronatine (Jiang et al. 2013).

The presence of the catalytic triad and the conserved lysine residue, being essential for the autoacetylation activity of YopJ-like effectors, are indicative that HopZ4 could act as an acetyltransferase (Lee et al. 2012; Mukherjee et al. 2006; Tasset et al. 2010). However, we could neither detect autoacetylation of HopZ4 nor acetyltransferase activity using recombinant HopZ4 in an acetylation assay with ${ }^{14} \mathrm{C}$-acetyl-CoA (data not shown). This is in accordance with the finding that XopJ also does not display acetyltransferase activity in vitro (Üstün et al. 2013). It has been shown that other members of the YopJ superfamily have weak cysteine protease activities in vitro (Ma et al. 2006; Szczesny et al. 2010). It is currently not known whether HopZ4 or XopJ possess protease activity. However, we reproducibly observed lower RPT6-GFP protein levels when the protein was coexpressed together with a functional HopZ4 protein, suggesting that HopZ4 destabilizes RPT6-GFP.

We could demonstrate that HopZ4 also interacts with RPT6 in plants and in yeast, indicating that HopZ4 exhibits XopJlike functions. The main difference between both effectors is the lack of an amino-terminal region in HopZ4 that is apparently not important for the recognition of RPT6, as a XopJ variant lacking this region is still able to interact with its target protein in yeast. This region could be important for the effector translocation or harbor XopJ-specific chaperone binding sites that are not present in HopZ4 (He et al. 2004; Mudgett et al. 2000). Nevertheless, it is conceivable that this region confers specific functions to XopJ, as has been shown for effectors from the XopD-like effector family from $X$. campestris pv. vesicatoria, which display variable amino-terminal domains (Kim et al. 2011).

RPT6 is a component of the $26 \mathrm{~S}$ proteasome that is responsible for the degradation of proteins involved in a range of cellular functions (Smalle and Vierstra 2004). The manipulation of the proteasome has emerged as an important virulence mechanism of plant pathogens (Dudler 2013). Several components of the proteasome and the proteasome function in general appear to be essential for SA-mediated defense signaling during pathogen-associated molecular pattern-triggered immunity (Misas-Villamil et al. 2013; Spoel et al. 2009; Üstün et al. 2013; Yao et al. 2012). Proteasome subunit RPT6 was shown to be essential for proteasome assembly in mammalian cells, and recent studies indicate that conformational changes in the C-terminal part of RPT6 facilitate complex formation in yeast (Ehlinger et al. 2013; Park et al. 2013; Satoh et al. 2001). Therefore, RPT6 likely constitutes an appropriate target for T3E proteins to impair proteasome function.

Another evidence for a functional conservation between HopZ4 and XopJ is the presence of the predicted N-myristoylation signal in HopZ4, directing the HopZ4-GFP fusion to the PM of plants. N-myristoylation sites have previously been shown to be an important feature of several bacterial T3E (AvrB, AvrPto, and HopF2), mediating the attachment of these effectors to the PM (Nimchuk et al. 2000; Robert-Seilaniantz et al. 2006; Shan et al. 2000). All members of the HopZ family except HopZ3 also contain a consensus myristoylation site, which is required for proper membrane localization (Lewis et al. 2008; Zhou et al. 2009). Recognition of HopZ1a by the R protein ZAR1 depends on its localization at the PM, whereas HopZ2 needs to be attached to the membrane for its virulence function (Lewis et al. 2008). The plant PM is a pivotal interface between the host plant and the pathogen, as essential components of the plant immune response are localized there. Thus, the localization of effectors at this interface is a crucial step to be able to suppress the innate immune response and defines their virulence or avirulence functions (Lewis et al. 2008; Robert-Seilaniantz et al. 2006; Shan et al. 2000; Üstün et al. 2013). Consistent with observations obtained by the functional analysis of XopJ (Bartetzko et al. 2009; Thieme et al. 2007), we found that mutation of the predicted N-myristoylation motif impairs membrane localization of HopZ4, resulting in a shift of the localization to the cytosol and nucleus. Nonetheless, it is possible that, apart from the myristoylation, other post-translational mechanisms are responsible for the PM attachment of HopZ4. Palmitoylation represents another mechanism to anchor proteins to the PM (Linder and Deschenes 2007). Just like XopJ, HopZ4 also contains a cysteine residue at the $\mathrm{N}$ terminus $(\mathrm{C} 3)$ that could be a target for palmitoylation (Thieme et al. 2007). In addition, a Cys at position 5 of HopZ1b was shown to be required for full elicitation of cell death in $N$. benthamiana, indicating that palmitoylation is necessary for this effector to be fully functional (Zhou et al. 2009). HopZ4 requires its enzymatic activity and localization to inhibit the proteasome activity. Although it is assumed that the proteasome is distributed between the cytosol and the nucleus of the cell, proteasomal subpopulations are also localized to the ER, cytoskeleton, or Golgi network (Rivett 1998; Wojcik and DeMartino 2003). A recent proteomics study demonstrated that, after induction of the effector-triggered immunity, the 
entire complement of the $19 \mathrm{~S}$ regulatory particles (RP) was detected within the PM fractions, suggesting that the 19S RP is somehow recruited to this compartment during plant defense (Elmore et al. 2012). The localization of HopZ4 to the plant PM appears to be essential for the suppression of the proteasome function. HopZ1a has previously been shown to require IP6 (phytic acid) for its activation within the host cell (Lee et al. 2012). Future experiments will need to address whether HopZ4 is also dependent on a eukaryotic factor for its activation at the PM.

RPT6 was found to be targeted by the $X$. campestris pv. vesicatoria effector XopJ to inhibit proteasome activity and, thereby, suppress SA-mediated defense signaling (Üstün et al. 2013). Moreover, $P$. syringae pv. syringae secretes a small nonribosomal peptide called syringolin A (SylA) that irreversibly inhibits the host cell proteasome to block SA signaling (Dudler 2013; Misas-Villamil et al. 2013). Overall, the inhibition of the host cell proteasome by Xanthomonas or Pseudomonas proteins appears to be an efficient strategy to interfere with SA-mediated signaling. Although, it is not clear whether $P$. syringae pv. lachrymans uses the same strategy to interfere with hormonal defense mechanisms, it is likely that HopZ4 functions similarly to XopJ in dampening the proteasome activity during infection. This idea is supported by the observation that HopZ4, when delivered by $X$. campestris pv. vesicatoria $\triangle x o p J$, complements the loss of XopJ, preventing precocious host cell death. Thus, HopZ4 acts as a proteasome inhibitor, possibly to interfere with SA-mediated signaling. In addition, HopZ4 is also able to inhibit secretion of a secGFP reporter, further strengthening the notion that HopZ4 has a similar function as XopJ. In conclusion, these data suggest that HopZ4 was acquired by Pseudomonas syringae pv. lachrymans as a means to interfere with the proteasome function. The ability to produce SylA is absent from this Pseudomonas strain (Baltrus et al. 2011). Based on previous findings on the interference of XopJ with SA-mediated defense responses (Üstün et al. 2013), we cautiously speculate that Pla107 secretes HopZ4 to suppress the proteasome activity in cucumber and, thereby, blocks SA-mediated signaling. This is also supported by the fact that the induction of the SAR by SA is the best way to protect cucumber plants from infection with $P$. syringae pv. lachrymans (Bhat et al. 2010).

The manipulation of the host cell proteasome is an efficient virulence mechanism of phytopathogens that are specialized on different host plants, providing a vivid example for the utilization of conserved effector molecules to target similar cellular processes.

\section{MATERIALS AND METHODS}

Plant material and growth conditions.

Pepper (Capsicum annuum cv. Early Cal Wonder) and tobacco plants (Nicotiana benthamiana) were grown in soil in a greenhouse with daily watering and were subjected to a $16-\mathrm{h}$ light and 8-h dark cycle (25 and $21^{\circ} \mathrm{C}$, respectively) at 300 $\mu \mathrm{mol} \mathrm{m} \mathrm{m}^{-2} \mathrm{~s}^{-1}$ of light and $75 \%$ relative humidity.

\section{Infection of pepper plants.}

$X$. campestris pv. vesicatoria infections were performed as described previously (Üstün et al. 2012). In brief, six-week-old plants were used for infection experiments. Bacterial cultures for inoculation were grown overnight in nutrient yeast gycerol medium containing $100 \mu \mathrm{g}$ of rifampicin per milliliter, were centrifuged at $5,000 \times g$ for $15 \mathrm{~min}$ at $4^{\circ} \mathrm{C}$, and were washed with $10 \mathrm{~mm}$ sterile $\mathrm{MgCl}_{2}$. Subsequently, cells were resuspended in $10 \mathrm{~mm}$ of $\mathrm{MgCl}_{2}$ and were adjusted to a final concentration of $1 \times 10^{5} \mathrm{CFU} \mathrm{ml}^{-1}$.
Yeast two-hybrid analysis.

Yeast two-hybrid techniques were performed according to the Yeast Protocols Handbook and the Matchmaker GAL4 TwoHybrid System 3 manual (Clontech, Heidelberg, Germany). The entire HopZ4 coding region was amplified by polymerase chain reaction (PCR) using the primers listed in Supplementary Table 1 and was inserted in the pGBT- 9 vector, generating a fusion with the GAL4 DNA-binding domain. Direct interaction of two proteins was investigated by cotransformation of the respective plasmids in yeast strain AH109, followed by selection of transformants on medium lacking Leu and Trp at $30^{\circ} \mathrm{C}$ for 3 days and subsequent transfer to medium lacking Leu, Trp, and His for growth selection and lacZ activity testing of interacting clones.

\section{Site-directed mutagenesis.}

Site-directed mutagenesis of HopZ4 constructs was carried out using the Quick-change site-directed mutagenesis kit (Stratagene, Heidelberg, Germany). All base changes were verified by sequencing.

\section{Plasmid construction for transient expression experiments.}

For the construction of binary vectors expressing HopZ4 and its mutant variants HopZ4G2A, C3A, G2AC3A, and C194A, the respective coding sequences were amplified by PCR. The resulting fragments were inserted into the $\mathrm{pENTR}-\mathrm{D} / \mathrm{TOPO}$ vector according to the manufacturer's instructions (Invitrogen, Karlsruhe, Germany San Diego, CA, U.S.A.) and sequences were verified. To generate translational fusions between HopZ4 and the GFP, coding sequences were inserted into the vector pK7FWG2 (Karimi et al. 2002), using L/R-Clonase (Invitrogen). For immunodetection after transient expression, the effector-encoding fragment was recombined into the plant expression vector pGWB614 (Nakamura et al. 2010).

\section{BiFC assay.}

Entry clones of HopZ4 and RPT6 comprising the entire coding region of each cDNA were used in a $\mathrm{L} / \mathrm{R}$ reaction with a Gateway System (Invitrogen)-compatible version of the BiFC

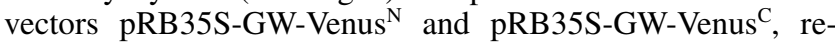
spectively. Constructs were transformed into Agrobacterium tumefaciens $\mathrm{C} 58 \mathrm{C} 1$ and transiently expressed by Agroinfiltration in $N$. benthamiana. The BiFC-induced YFP fluorescence was detected by confocal laser scanning microscopy on a Leica TCS SP5II after 48 hpi.

\section{Agroinfiltration.}

For infiltration of $N$. benthamiana leaves, A. tumefaciens $\mathrm{C} 58 \mathrm{C} 1$ was infiltrated into the abaxial air space of four- to sixweek-old plants, using a needleless 2-ml syringe. Agrobacteria were cultivated overnight at $28^{\circ} \mathrm{C}$ in the presence of appropriate antibiotics. The cultures were harvested by centrifugation, and the pellet was resuspended in sterile water to a final optical density at $600 \mathrm{~nm}$ of 1.0 . The cells were used for the infiltration directly after resuspension. Infiltrated plants were further cultivated in the greenhouse with daily watering and were subjected to a 16-h light and 8-h dark cycle $\left(25\right.$ and $21^{\circ} \mathrm{C}$, respectively) at $300 \mu \mathrm{mol} \mathrm{m} \mathrm{m}^{-2} \mathrm{~s}^{-1}$ of light and $75 \%$ relative humidity.

\section{Western blotting.}

Leaf material was homogenized in sodium-dodecyl sulphate (SDS)-polyacrylamide gel electrophoresis loading buffer (100 $\mathrm{mM}$ Tris- $\mathrm{HCl}, \mathrm{pH} 6.8,9 \% \beta$-mercapto ethanol, $40 \%$ glycerol, $0.0005 \%$ bromophenol blue, $4 \%$ SDS) and, after heating for $10 \mathrm{~min}$ at $95^{\circ} \mathrm{C}$, was subjected to electrophoresis. Separated proteins were transferred onto nitrocellulose membrane (Pora- 
blot; Machery and Nagel, Düren, Germany). Proteins were detected by either an anti-HA antibody (Sigma, St. Louis), antimyc antibody (Santa Cruz Biotechnology), anti-GFP antibody (Roche, Mannheim, Germany), or anti-ubiquitin antibody (Agrisera) via chemiluminescence (GE Healthcare, Piscataway, NJ, U.S.A.).

Translocation of HopZ4-HA by X. campestris pv. vesicatoria.

Construction of fusion proteins, cloning into the broad hostrange vector pBBR1-MCS5 (Kovach et al. 1995), and introduction of the construct into $X$. campestris pv. vesicatoria $\Delta x o p J$ was described previously (Üstün et al. 2012).

\section{Measurement of proteasome activity.}

Proteasome activity in crude plant extracts was determined spectrofluorometrically, using the fluorogenic substrate sucLLVY-NH-Mec (Sigma) according to Üstün and associates (2013). In brief, four leaf discs with a diameter of $0.7 \mathrm{~cm}$ each were harvested and frozen in liquid nitrogen. The leaf material was ground in $200 \mu \mathrm{l}$ of extraction buffer [50 mM HEPES$\mathrm{KOH}, \mathrm{pH} 7.2,2 \mathrm{mM}$ adenosine triphosphate (ATP), $2 \mathrm{mM}$ dithiothreitol (DTT), $250 \mathrm{mM}$ sucrose]. After centrifugation, the protein concentration of the supernatant was adjusted with extraction buffer to $1 \mathrm{mg} / \mathrm{ml}$. Total protein $(50 \mu \mathrm{g})$ was mixed with $220 \mu \mathrm{l}$ of proteolysis buffer [100 mM HEPES-KOH, $\mathrm{pH}$ 7.8, $5 \mathrm{mM} \mathrm{MgCl}_{2}, 10 \mathrm{mM} \mathrm{KCl}, 2 \mathrm{mM}$ ATP]. The reaction was started after $5 \mathrm{~min}$ at $30^{\circ} \mathrm{C}$ by the addition $0.2 \mathrm{mM}$ suc-LLVYAMC. The breakdown of the peptide was continuously monitored for $3 \mathrm{~h}$, using a fluorescence spectrophotometer (FLX800, BioTek, Winooski, VT, U.S.A.), with an excitation wavelength of $360 \mathrm{~nm}$ and an emission wavelength of $460 \mathrm{~nm}$.

\section{Protein extraction and GFP-pull down in N. benthamiana.}

GFP pull-down assays were carried out according to Schwessinger and associates (2011), with slight modifications. Approximately $1 \mathrm{~g}$ of leaf material was ground to fine powder in liquid nitrogen and $5 \mathrm{ml}$ of extraction buffer $(50 \mathrm{mM}$ Tris$\mathrm{HCl}, \mathrm{pH} 7.5,150 \mathrm{mM} \mathrm{NaCl}, 10 \%$ glycerol, $10 \mathrm{mM}$ DTT, 10 mM EDTA, $1 \mathrm{mM} \mathrm{NaF,} 1 \mathrm{mM} \mathrm{Na} 2 \mathrm{MoO}_{4} \cdot 2 \mathrm{H}_{2} \mathrm{O}, 1 \%$ [wt/vol] polyvinylpolypyrrolidone, $1 \%$ [vol/vol] $\mathrm{P} 9599$ protease inhibitor cocktail [Sigma], 1\% [vol/vol] NP-40) was added. Samples were cleared by centrifugation at $16.000 \times g$ for $15 \mathrm{~min}$ at $4{ }^{\circ} \mathrm{C}$ and were adjusted to a total protein concentration of $2 \mathrm{mg} / \mathrm{ml}$. Immunoprecipitation was performed on $1.5 \mathrm{ml}$ of total protein by adding $20 \mu \mathrm{l}$ of GFPTrap-M beads (Chromotek, Martinsried, Germany) and incubation was at $4^{\circ} \mathrm{C}$ for 3 to $4 \mathrm{~h}$. Beads were washed four times with Tris-buffered saline containing $0.5 \%$ (vol/vol) NP-40, immunoprecipitates were eluted with $30 \mu \mathrm{l}$ of $2 \times \operatorname{SDS}$ loading buffer and were heated at $70^{\circ} \mathrm{C}$ for $10 \mathrm{~min}$.

\section{Ion leakage measurements.}

For electrolyte leakage experiments, triplicates of $1.76-\mathrm{cm}^{2}$ infected leaf material were taken 24 and 48 hpi. Leaf discs were placed on the bottom of a $15-\mathrm{ml}$ tube and $8 \mathrm{ml}$ of deionized water was added to each tube. After $24 \mathrm{~h}$ of incubation in a rotary shaker at $4^{\circ} \mathrm{C}$, conductivity was determined with a conductometer. To measure maximum conductivity of the entire sample, conductivity was determined after boiling the samples for $30 \mathrm{~min}$ (Stall et al. 1974).

\section{Trypan blue staining.}

To visualize dying cells, leaves were detached and submerged in lactophenol-trypan blue solution (0.03\% trypan blue, 33\% [wt/vol] lactic acid, 33\% water-saturated phenol, and 33\% glycerol). Samples were incubated at $99^{\circ} \mathrm{C}$ for $1 \mathrm{~min}$, followed by incubation at room temperature for $24 \mathrm{~h}$, were washed in chloral hydrate solution $\left(2.5 \mathrm{~g} \mathrm{ml}^{-1}\right)$ to reduce background staining, and were photographed using a Leica MZLIII stereomicroscope (Leica Microsystems, Wetzlar, Germany).

\section{Colocalization and confocal laser scanning microscopy.}

Localization experiments were performed as described previously (Bartetzko et al. 2009).

\section{ACKNOWLEDGMENTS}

This work was supported by a grant from the Deutsche Forschungsgemeinschaft (SFB 796: Reprogramming of host cells by microbial effectors). We thank C. Symowksi for excellent technical assistance. The experiments were conceived and designed by $\mathrm{S}$. Üstün and F. Börnke, S. Üstün and P. König performed the experiments, D. S. Guttman contributed novel reagents and materials, S. Üstün, P. König, and F. Börnke analyzed the data, and S. Üstün and F. Börnke wrote the paper.

\section{LITERATURE CITED}

Baltrus, D. A., Nishimura, M. T., Romanchuk, A., Chang, J. H., Mukhtar, M. S., Cherkis, K., Roach, J., Grant, S. R., Jones, C. D., and Dangl, J. L. 2011. Dynamic evolution of pathogenicity revealed by sequencing and comparative genomics of 19 Pseudomonas syringae isolates. PLoS Pathog. 7:e1002132. Published online.

Bartetzko, V., Sonnewald, S., Vogel, F., Hartner, K., Stadler, R., Hammes, U. Z., and Börnke, F. 2009. The Xanthomonas campestris pv. vesicatoria type III effector protein XopJ inhibits protein secretion: Evidence for interference with cell wall-associated defense responses. Mol. PlantMicrobe Interact. 22:655-664.

Batistic, O., Sorek, N., Schultke, S., Yalovsky, S., and Kudla, J. 2008. Dual fatty acyl modification determines the localization and plasma membrane targeting of CBL/CIPK Ca2+ signaling complexes in Arabidopsis. Plant Cell 20:1346-1362.

Batoko, H., Zheng, H. Q., Hawes, C., and Moore, I. 2000. A rab1 GTPase is required for transport between the endoplasmic reticulum and Golgi apparatus and for normal Golgi movement in plants. Plant Cell 12:2201-2218.

Bhat, N. A., Bhat, K. A., Zargar, M. Y., Teli, M. A., Nazir, M., and Zargar, S. M. 2010. Current status of angular leaf spot (Pseudomonas syringae pv. lachrymans) of cucumber: A review. Int. J. Curr. Res. 8:001-011.

Cunnac, S., Chakravarthy, S., Kvitko, B. H., Russell, A. B., Martin, G. B., and Collmer, A. 2011. Genetic disassembly and combinatorial reassembly identify a minimal functional repertoire of type III effectors in Pseudomonas syringae. Proc. Natl. Acad. Sci. U.S.A. 108:2975-2980.

Deslandes, L., and Rivas, S. 2012. Catch me if you can: Bacterial effectors and plant targets. Trends Plant Sci. 17:644-655.

Du, F., and Galan, J. E. 2009. Selective inhibition of type III secretion activated signaling by the Salmonella effector AvrA. PLoS Pathog 5:e1000595. Published online.

Dudler, R. 2013. Manipulation of Host Proteosomes as a Virulence Mechanism of Plant Pathogens. Ann. Rev. Phytopathol. 51:521-542.

Ehlinger, A., Park, S., Fahmy, A., Lary, J. W., Cole, J. L., Finley, D., and Walters, K. J. 2013. Conformational dynamics of the rpt6 ATPase in proteasome assembly and rpn14 binding. Structure 21:753-765.

Elmore, J. M., Liu, J., Smith, B., Phinney, B., and Coaker, G. 2012. Quantitative proteomics reveals dynamic changes in the plasma membrane during Arabidopsis immune signaling. Mol. Cell Prot. 11:M111 014555. Published online.

Göhre, V., Spallek, T., Haweker, H., Mersmann, S., Mentzel, T., Boller, T., de Torres, M., Mansfield, J. W., and Robatzek, S. 2008. Plant patternrecognition receptor FLS2 is directed for degradation by the bacterial ubiquitin ligase AvrPtoB. Curr. Biol. 18:1824-1832.

Groll, M., Schellenberg, B., Bachmann, A. S., Archer, C. R., Huber, R., Powell, T. K., Lindow, S., Kaiser, M., and Dudler, R. 2008. A plant pathogen virulence factor inhibits the eukaryotic proteasome by a novel mechanism. Nature 452:755-758.

Hatsugai, N., Iwasaki, S., Tamura, K., Kondo, M., Fuji, K., Ogasawara, K., Nishimura, M., and Hara-Nishimura, I. 2009. A novel membrane fusion-mediated plant immunity against bacterial pathogens. Genes Dev. 23:2496-2506.

He, S. Y., Nomura, K., and Whittam, T. S. 2004. Type III protein secretion mechanism in mammalian and plant pathogens. Biochim. Biophys. Acta 1694:181-206.

Hofstetter, S. S., Dudnik, A., Widmer, H., and Dudler, R. 2013. Arabidopsis YELLOW STRIPE-LIKE7 (YSL7) and YSL8 transporters mediate uptake of Pseudomonas virulence factor syringolin A into plant cells. 
Mol. Plant-Microbe Interact. 26:1302-1311.

Hotson, A., and Mudgett, M. B. 2004. Cysteine proteases in phytopathogenic bacteria: Identification of plant targets and activation of innate immunity. Curr. Opin. Plant Biol. 7:384-390.

Janjusevic, R., Abramovitch, R. B., Martin, G. B., and Stebbins, C. E. 2006. A bacterial inhibitor of host programmed cell death defenses is an E3 ubiquitin ligase. Science 311:222-226.

Karimi, M., Inzé, D., and Depicker, A. 2002. GATEWAY ${ }^{\mathrm{TM}}$ vectors for Agrobacterium-mediated plant transformation. Trends Plant Sci. 7:193195

Jiang, S., Yao, J., Ma, K.-W., Zhou, H., Song, J., He, S. Y., and Ma, W. 2013. Bacterial effector activates jasmonate signaling by directly targeting JAZ transcriptional repressors. PLoS Pathog. 9:e1003715. Published online.

Kim, J. G., Taylor, K. W., and Mudgett, M. B. 2011. Comparative analysis of the XopD type III secretion (T3S) effector family in plant pathogenic bacteria. Mol. Plant Pathol. 12:715-730.

Kimbrel, J. A., Thomas, W. J., Jiang, Y., Creason, A. L., Thireault, C. A., Sachs, J. L., and Chang, J. H. 2013. Mutualistic co-evolution of type III effector genes in Sinorhizobium fredii and Bradyrhizobium japonicum. PLoS Pathog. 9:e1003204. Published online.

Kovach, M. E., Elzer, P. H., Hill, D. S., Robertson, G. T., Farris, M. A., Roop, R. M., 2nd, and Peterson, K. M. 1995. Four new derivatives of the broad-host-range cloning vector pBBR1MCS, carrying different antibiotic-resistance cassettes. Gene 166:175-176.

Lee, A. H., Hurley, B., Felsensteiner, C., Yea, C., Ckurshumova, W., Bartetzko, V., Wang, P. W., Quach, V., Lewis, J. D., Liu, Y. C., Börnke, F., Angers, S., Wilde, A., Guttman, D. S., and Desveaux, D. 2012. A bacterial acetyltransferase destroys plant microtubule networks and blocks secretion. PLoS Pathog. 8:e1002523. Published online.

Lee, A. H., Middleton, M. A., Guttman, D. S., and Desveaux, D. 2013. Phytopathogen type III effectors as probes of biological systems. Microb. Biotechnol. 6:230-240.

Lewis, J. D., Abada, W., Ma, W., Guttman, D. S., and Desveaux, D. 2008 The HopZ family of Pseudomonas syringae type III effectors require myristoylation for virulence and avirulence functions in Arabidopsis thaliana. J. Bacteriol. 190:2880-2891.

Lewis, J. D., Lee, A., Ma, W., Zhou, H., Guttman, D. S., and Desveaux, D. 2011. The YopJ superfamily in plant-associated bacteria. Mol. Plant Pathol. 12:928-937.

Linder, M. E., and Deschenes, R. J. 2007. Palmitoylation: Policing protein stability and traffic. Nature reviews. Mol. Cell Biol. 8:74-84.

Lu, D., Lin, W., Gao, X., Wu, S., Cheng, C., Avila, J., Heese, A., Devarenne, T. P., He, P., and Shan, L. 2011. Direct ubiquitination of pattern recognition receptor FLS2 attenuates plant innate immunity. Science 332:14391442 .

Ma, W., Dong, F. F. T., Stavrinides, J., and Guttman, D. S. 2006. Diversification of a type III effector family via both pathoadaptation and horizontal transfer in response to a coevolutionary arms race. PLoS Genet. 12:e209. Published online.

Marino, D., Peeters, N., and Rivas, S. 2012. Ubiquitination during plant immune signaling. Plant Physiol. 160:15-27.

Misas-Villamil, J. C., Kolodziejek, I., Crabill, E., Kaschani, F., Niessen, S., Shindo, T., Kaiser, M., Alfano, J. R., and van der Hoorn, R. A. 2013. Pseudomonas syringae pv. syringae uses proteasome inhibitor syringolin A to colonize from wound infection sites. PLoS Pathog. 9:e1003281. Published online.

Mittal, R., Peak-Chew, S. Y., Sade, R. S., Vallis, Y., and McMahon, H. T. 2010. The acetyltransferase activity of the bacterial toxin YopJ of Yersinia is activated by eukaryotic host cell inositol hexakisphosphate. J. Biol. Chem. 285:19927-19934.

Mudgett, M. B., Chesnokova, O., Dahlbeck, D., Clark, E. T., Rossier, O., Bonas, U., and Staskawicz, B. J. 2000. Molecular signals required for type III secretion and translocation of the Xanthomonas campestris AvrBs2 protein to pepper plants. Proc. Natl. Acad. Sci. U.S.A. 97:13324-13329.

Mukherjee, S., Keitany, G., Li, Y., Wang, Y., Ball, H. L., Goldsmith, E. J., and Orth, K. 2006. Yersinia YopJ acetylates and inhibits kinase activation by blocking phosphorylation. Science 312:1211-1214.

Nakamura, S., Mano, S., Tanaka, Y., Ohnishi, M., Nakamori, C., Araki, M., Niwa, T., Nishimura, M., Kaminaka, H., Nakagawa, T., Sato, Y., and Ishiguro, S. 2010. Gateway binary vectors with the bialaphos resistance gene, bar, as a selection marker for plant transformation. Biosci. Biotechnol. Biochem. 74:1315-1319.

Nimchuk, Z., Marois, E., Kjemtrup, S., Leister, R. T., Katagiri, F., and Dangl, J. L. 2000. Eukaryotic fatty acylation drives plasma membrane targeting and enhances function of several type III effector proteins from Pseudomonas syringae. Cell 101:353-363.

Nomura, K., Debroy, S., Lee, Y. H., Pumplin, N., Jones, J., and He, S. Y. 2006. A bacterial virulence protein suppresses host innate immunity to cause plant disease. Science 313:220-223.

O’Brien, H. E., Thakur, S., Gong, Y., Fung, P., Zhang, J., Yuan, L., Wang, P. W., Yong, C., Scortichini, M., and Guttman, D. S. 2012. Extensive remodeling of the Pseudomonas syringae pv. avellanae type III secretome associated with two independent host shifts onto hazelnut. BMC Microbiol. 12:141.

Orth, K. 2002. Function of the Yersinia effector YopJ. Curr. Opin. Microbiol. 5:38-43.

Orth, K., Xu, Z. H., Mudgett, M. B., Bao, Z. Q., Palmer, L. E., Bliska, J. B., Mangel, W. F., Staskawicz, B., and Dixon, J. E. 2000. Disruption of signaling by Yersinia effector YopJ, a ubiquitin-like protein protease. Science 290:1594-1597.

Park, S., Li, X., Kim, H. M., Singh, C. R., Tian, G., Hoyt, M. A., Lovell, S., Battaile, K. P., Zolkiewski, M., Coffino, P., Roelofs, J., Cheng, Y., and Finley, D. 2013. Reconfiguration of the proteasome during chaperone-mediated assembly. Nature 497:512-516.

Rivett, A. J. 1998. Intracellular distribution of proteasomes. Curr. Opin. Immunol. 10:110-114.

Robert-Seilaniantz, A., Shan, L., Zhou, J. M., and Tang, X. 2006. The Pseudomonas syringae pv. tomato DC3000 type III effector HopF2 has a putative myristoylation site required for its avirulence and virulence functions. Mol. Plant-Microbe Interact. 19:130-138.

Roden, J. A., Belt, B., Ross, J. B., Tachibana, T., Vargas, J., and Mudgett M. B. 2004. A genetic screen to isolate type III effectors translocated into pepper cells during Xanthomonas infection. Proc. Natl. Acad. Sci. U.S.A. 101:16624-16629.

Satoh, K., Sasajima, H., Nyoumura, K. I., Yokosawa, H., and Sawada, H 2001. Assembly of the $26 \mathrm{~S}$ proteasome is regulated by phosphorylation of the p45/Rpt6 ATPase subunit. Biochemistry 40:314-319.

Schulze, S., Kay, S., Buttner, D., Egler, M., Eschen-Lippold, L., Hause, G., Kruger, A., Lee, J., Muller, O., Scheel, D., Szczesny, R., Thieme, F. and Bonas, U. 2012. Analysis of new type III effectors from Xanthomonas uncovers XopB and XopS as suppressors of plant immunity. New Phytol. 195:894-911.

Schwessinger, B., Roux, M., Kadota, Y., Ntoukakis, V., Sklenar, J., Jones, A., and Zipfel, C. 2011. Phosphorylation-dependent differential regulation of plant growth, cell death, and innate immunity by the regulatory receptor-like kinase BAK1. PLoS Genet. 7:e1002046. Published online.

Shan, L. B., Thara, V. K., Martin, G. B., Zhou, J. M., and Tang, X. Y. 2000. The pseudomonas AvrPto protein is differentially recognized by tomato and tobacco and is localized to the plant plasma membrane. Plant Cell $12: 2323-2337$.

Smalle, J., and Vierstra, R. D. 2004. The ubiquitin 26S proteasome proteolytic pathway. Ann. Rev. Plant Biol. 55:555-590.

Spoel, S. H., Mou, Z., Tada, Y., Spivey, N. W., Genschik, P., and Dong, X 2009. Proteasome-mediated turnover of the transcription coactivator NPR1 plays dual roles in regulating plant immunity. Cell 137:860-872.

Stall, R. E., Bartz, J. A., and Cook, A. A. 1974. Decreased hypersensitivity to xanthomonads in pepper after inoculations with virulent cells of Xanthomonas vesictoria. Phytopathology 64:731-735.

Stegmann, M., Anderson, R. G., Ichimura, K., Pecenkova, T., Reuter, P., Zarsky, V., McDowell, J. M., Shirasu, K., and Trujillo, M. 2012. The ubiquitin ligase PUB22 targets a subunit of the exocyst complex required for PAMP-triggered responses in Arabidopsis. Plant Cell 24:4703-4716.

Szczesny, R., Buttner, D., Escolar, L., Schulze, S., Seiferth, A., and Bonas, U. 2010. Suppression of the AvrBs1-specific hypersensitive response by the YopJ effector homolog AvrBsT from Xanthomonas depends on a SNF1-related kinase. New Phytol. 187:1058-1074.

Tasset, C., Bernoux, M., Jauneau, A., Pouzet, C., Briere, C., KiefferJacquinod, S., Rivas, S., Marco, Y., and Deslandes, L. 2010. Autoacetylation of the Ralstonia solanacearum effector PopP2 targets a lysine residue essential for RRS1-R-mediated immunity in Arabidopsis. PLoS Pathog. 6:e1001202. Published online.

Thieme, F., Szczesny, R., Urban, A., Kirchner, O., Hause, G., and Bonas, U. 2007. New type III effectors from Xanthomonas campestris pv. vesicatoria trigger plant reactions dependent on a conserved N-myristoylation motif. Mol. Plant-Microbe Interact. 20:1250-1261.

Trujillo, M., Ichimura, K., Casais, C., and Shirasu, K. 2008. Negative regulation of PAMP-triggered immunity by an E3 ubiquitin ligase triplet in Arabidopsis. Curr. Biol. 18:1396-1401.

Üstün, S., Muller, P., Palmisano, R., Hensel, M., and Börnke, F. 2012 SseF, a type III effector protein from the mammalian pathogen Salmonella enterica, requires resistance-gene-mediated signalling to activate cell death in the model plant Nicotiana benthamiana. New Phytol. 194:1046-1060.

Üstün, S., Bartetzko, V., and Börnke, F. 2013. The Xanthomonas campestris type III effector XopJ targets the host cell proteasome to suppress salicylic-acid mediated plant defence. PLoS Pathog. 9:e1003427. Published online. 
Wojcik, C., and DeMartino, G. N. 2003. Intracellular localization of proteasomes. Int. J. Biochem. Cell B 35:579-589.

Xin, X. F., and He, S. Y. 2013. Pseudomonas syringae pv. tomato DC3000: A model pathogen for probing disease susceptibility and hormone signaling in plants. Ann. Rev. Phytopathol. 51:473-498.

Yao, C., Wu, Y., Nie, H., and Tang, D. 2012. RPN1a, a 26S proteasome subunit, is required for innate immunity in Arabidopsis. Plant $\mathrm{J}$. 71:1015-1028.

Zheng, Y., Lilo, S., Brodsky, I. E., Zhang, Y., Medzhitov, R., Marcu, K. B., and Bliska, J. B. 2011. A Yersinia effector with enhanced inhibitory activity on the NF-kappaB pathway activates the NLRP3/ASC/caspase-1 inflammasome in macrophages. PLoS Pathog. 7:e1002026. Published online.

Zhou, H., Monack, D. M., Kayagaki, N., Wertz, I., Yin, J., Wolf, B., and Dixit, V. M. 2005. Yersinia virulence factor YopJ acts as a deubiquitinase to inhibit NF-kappa B activation. J. Exp. Med. 202:1327-1332.

Zhou, H., Morgan, R. L., Guttman, D. S., and Ma, W. 2009. Allelic variants of the Pseudomonas syringae type III effector HopZ1 are differentially recognized by plant resistance systems. Mol. Plant-Microbe Interact.22:176-189.

Zhou, H., Lin, J., Johnson, A., Morgan, R. L., Zhong, W., and Ma, W. 2011. Pseudomonas syringae type III effector HopZ1 targets a host enzyme to suppress isoflavone biosynthesis and promote infection in soybean. Cell Host Microbe 9:177-186. 